\title{
Avaliação de políticas públicas: uma revisão teórica de um campo em construção*
}

\author{
Andrei Pittol Trevisan** \\ Hans Michael van Bellen***
}

SumáR Io: 1. Introdução; 2 . Avaliação de políticas públicas; 3. Breve histórico sobre a avaliação de políticas públicas; 4. Do "estado de campo" de avaliação de políticas públicas; 5. Metodologia de avaliação de políticas públicas; 6 . Considerações finais.

Summary: 1. Introduction; 2. Evaluation of public policy; 3. Brief narrative on evaluation of public policy; 4. State of the discipline of the evaluation of public policy; 5. Methodology of public policy evaluation; 6. Final remarks.

Palavras-chave: políticas públicas; avaliação de políticas públicas; metodologias de avaliação de políticas públicas.

KEY WORDS: public policy; evaluation of public policy; methodologies of evaluation of public policy.

Este artigo realiza um resgate teórico da literatura sobre a área de políticas públicas em geral, e de avaliação de políticas públicas especificamente. O conhecimento teórico-histórico de um dado campo do conhecimento é essencial para sua práxis, para uma melhor compreensão dos seus desdobramentos, sua trajetória e perspectivas. O

\footnotetext{
* Artigo recebido em ago. 2007 e aceito em mar. 2008.

** Graduado em administração pela Universidade Federal de Santa Catarina. Mestrando em administração na Universidade Federal de Santa Catarina. Pesquisador e participante do Observatório da Realidade Organizacional (UFSC/Fundação Getulio Vargas-RJ/UFPE). Endereço: Rua Vitor Konder, 302, Residencial Linda Koerich, ap. 1405 - CEP 88015-400, Florianópolis, SC, Brasil. E-mail: andreipt@hotmail.com.

*** Professor permanente do Curso de Pós-Graduação em Administração e do Programa de PósGraduação em Contabilidade da Universidade Federal de Santa Catarina. Endereço: Caixa Postal 10042 — CEP 88062-970, Lagoa da Conceição, Florianópolis, SC, Brasil. E-mail: hansmichael@ cse.ufsc.br.
} 
artigo começa com uma explanação sobre políticas públicas, sua origem e dimensões conceituais. Continua com uma discussão a respeito dessa temática no Brasil, principalmente nos últimos anos. A avaliação de políticas públicas é observada com maior profundidade, atravessando diversas definições conferidas pela literatura. Destaca-se a identificação de três fases da avaliação desde a década de 1960 até os dias atuais. Posteriormente, apresentam-se metodologias de avaliação de políticas públicas, suas diversas classificações, timing, posição do avaliador, critérios e estruturação. Por fim, a possibilidade de aplicação de metaavaliações, assim como o surgimento de novas issues que se impõem ao contexto democrático-participativo brasileiro.

Evaluating public policies: a theoretical review of a field under construction This article performs a theoretical recovery of the literature about public policy in general, and evaluation of public policy specifically. The theoretical and historical understanding of a given field of knowledge is essential for its practice, including a better understanding of its consequences, its trajectory, and perspectives. The article begins with a general overview about public policy, its origins, and conceptual dimensions. It then continues with a discussion about this theme in Brazil, taking into consideration mainly the more recent years. The evaluation of public policy is observed more deeply for it has received numerous definitions within the literature. Three main phases of evaluation are identified since the 1960s until the present date. Subsequently the article presents some methodologies concerning the evaluation of public policy, including its several classifications, timing, the evaluator's position, criteria and structure. Finally, it comments on the possibility of the application of meta-evaluations, as well as on the emergence of new issues that impose themselves into the participative-democratic Brazilian context.

\section{Introdução}

No final do século XX, com o aprofundamento da crise do welfare state, com as convulsões econômicas, sociais e políticas enfrentadas, principalmente a partir do final da década de 1970, junto com o movimento da nova administração pública, o Estado é fortemente questionado tanto em suas funções quanto na real eficácia de suas ações interventoras na realidade social. Aceitando-se que a compreensão do sucesso e do fracasso das políticas públicas é fundamental para o melhor desempenho da administração pública, passa-se a algumas considerações sobre o "Estado em ação". ${ }^{1}$

De acordo com Faria (2003), em seus primórdios, as políticas públicas eram consideradas quase exclusivamente outputs do sistema político, o que

\footnotetext{
${ }^{1}$ Termo cunhado por Jobert e Muller, 1987.
} 
justificava o fato de a atenção dos investigadores ter se concentrado inicialmente nos inputs, isto é, nas demandas e articulações de interesse. Dessa forma, antes que a análise de políticas públicas fosse reconhecida como uma subárea da ciência política, os estudos recaíam nos processos de formação de políticas públicas, "o que parece refletir o status privilegiado que os processos decisórios sempre desfrutaram junto aos profissionais da área" (Faria, 2003:21).

Nos Estados Unidos, segundo Frey (2000), pesquisas em políticas públicas começaram a se estabelecer no início dos anos 1950, sob a designação de policy science, enquanto na Europa, especialmente na Alemanha, a preocupação com campos específicos de políticas somente toma força a partir do início dos anos 1970. Nesse período a unidade de análise torna-se a própria definição das políticas públicas, o que conferiu destaque aos aspectos dinâmicos do policy process e aos distintos atores, estatais e não-estatais, geralmente envolvidos (Faria, 2003). No caso do Brasil, os estudos sobre políticas públicas são bem recentes. Nesses estudos dispersos, a ênfase recaiu ou à análise das estruturas e instituições ou à caracterização dos processos de negociação das políticas setoriais específicas.

Para Faria (2003), há atualmente uma Babel de abordagens, teorizações incipientes e vertentes analíticas que buscam dar significação à diversificação dos processos de formação e gestão das políticas públicas, considerando um mundo cada vez mais caracterizado pela interdependência assimétrica, incerteza e complexidade das questões. Assim, para que se possa entender melhor a análise das políticas, Frey (2000) apresenta algumas categorias que têm conseguido relevância na literatura, com ênfase em policy cycle (ciclo político).

O agir público pode ser dividido em fases parciais do processo políticoadministrativo de resolução de problemas, que correspondem a uma seqüência de elementos do processo. Comum a todas as propostas de divisões do ciclo político são as fases da formulação, da implementação e do controle dos impactos das políticas (Frey, 2000).

Para os fins deste artigo, destaca-se a última fase do ciclo político, a avaliação de políticas e da correção de ação (evaluation), na qual se apreciam os programas já implementados no que diz respeito aos seus impactos efetivos. Investigam-se os déficits de impacto e os efeitos colaterais indesejados para poder extrair conseqüências para ações e programas futuros. Nessa etapa, caso os objetivos do programa tenham sido atendidos, o ciclo político pode ser suspenso ou chegar ao fim, senão à iniciação de um novo ciclo, isto é, a uma nova fase de percepção e definição de problemas. "Com isso, a fase da avaliação é imprescindível para o desenvolvimento e a adaptação contínua das formas e instrumentos de ação pública" (Frey, 2000:229). 
Na concepção apresentada do modelo de policy cycle o processo para resolução de um problema tem uma seqüência de fases. Na prática, segundo Frey (2000), os atores político-administrativos dificilmente se fixam a esse contínuo, especialmente para programas políticos mais complexos que se baseiam em processos interativos, cuja dinâmica é movida por reações mútuas dos atores envolvidos. Assim, o policy cycle pode servir como um quadro de referência para a análise processual.

\section{Políticas públicas no Brasil}

De acordo com Melo (1998), a construção histórica da agenda de políticas públicas no Brasil pode ser identificada e dividida em etapas. Porém, não se pretende um aprofundamento detalhado em cada etapa, apenas uma descrição sumária dos últimos anos e seus destaques.

A análise de políticas públicas experimentou um boom na década de 1980, impulsionada pela transição democrática. São três os motivos da expansão (Melo, 1999). Em primeiro lugar, pelo deslocamento na agenda pública. Durante os anos 1970, a agenda pública se estruturou em torno de questões relativas ao modelo brasileiro de desenvolvimento, onde a discussão limitava-se aos impactos redistributivos da ação governamental e ao tipo de racionalidade que conduzia o projeto de modernização conservadora do regime ditatorial. Eram centrais para essa agenda as questões de arranjo institucional: descentralização, participação, transparência e redefinição do mix público-privado nas políticas. A essa transformação da agenda seguiu-se uma redescoberta na agenda de pesquisas das políticas municipais e descentralização.

Em segundo lugar, não obstante o fim do período autoritário, constatouse que os obstáculos à consecução de políticas sociais efetivas continuaram existindo, o que serviu para fortalecer os estudos sobre políticas. A perplexidade e o desencantamento em relação ao Estado levaram a um maior interesse sobre as condições de efetividade da ação pública.

Em terceiro lugar, a difusão internacional da idéia de reforma do Estado e do aparelho de Estado passou a ser o princípio organizador da agenda pública dos anos 1980-90, o que provocou uma proliferação de estudos de políticas públicas. As questões de arranjo institucional ganharam grande centralidade na agenda: “(...) ao tomar-se o modo e a qualidade da intervenção pública na economia e na sociedade como objeto de estudo, cria-se por extensão um programa de pesquisa de caráter empírico sobre questões relativas à eficiência de políticas e programas" (Melo, 1999:81). Por outro lado, se antes o encanta- 
mento da imaginação social brasileira era o Estado, nos anos 1990, esse apego passa a ser direcionado, paulatinamente, para a sociedade civil.

De fato, nos últimos anos tem-se visto um crescimento dos estudos da área de políticas públicas no Brasil (Arretche, 2003; Souza, 2003). Conforme Arretche (2003), multiplicaram-se as dissertações e teses sobre temas relacionados às políticas governamentais; disciplinas de políticas públicas foram criadas ou inseridas nos programas de graduação e pós-graduação; criaramse linhas de pesquisa especialmente voltadas para essa área; instituíram-se agências de fomento à pesquisa, assim como linhas especiais de financiamento para a área.

Apoiando-se em Melo (1999), Arretche (2003) confirma que a área de políticas públicas no Brasil se caracteriza por uma baixa capacidade de acumulação de conhecimento, em função da proliferação horizontal de estudos de caso e da ausência de pesquisa. Souza (2003) diz que esse é o primeiro problema a ser superado pela área. A solução, felizmente, tem avançado com a criação de fóruns específicos sobre políticas públicas em espaços acadêmicos, e com o advento da informatização de periódicos nacionais e internacionais. ${ }^{2}$ "Esses fóruns e instrumentos permitem-nos conhecer melhor e mais rapidamente a produção de nossos pares, embora não exista um periódico específico que abrigue exclusivamente a produção da área" (Souza, 2003:16).

Reis (2003) assinala que a política pública não se furta ao imperativo da utilidade social, ou seja, mesmo quando adota uma postura crítica, ela o faz apostando na possibilidade de cursos de ação alternativos. Portanto, há poucas dúvidas quanto ao objeto de análise de políticas públicas. A análise do "Estado em ação" tem como objeto específico o estudo de programas governamentais, suas condições de emergência, mecanismos de operação e prováveis impactos sobre a ordem social e econômica (Arretche, 2003).

Por ser uma subárea muito ampla, decorre outro problema, ressaltado por Souza (2003) e comentado por Melo (1999): a abundância de estudos setoriais, dotando a área de uma diversificação de objetos empíricos que se expandem horizontalmente, sem um fortalecimento vertical da produção. Conforme a autora, isso acontece porque a disciplina envolve, no mínimo, análises sobre a identificação do problema que vai ou não se transformar em uma política (agenda setting), a formulação, a legitimação, gestão, implementação e avaliação da política. É da essência da área a multidisciplinaridade, razão pela qual estudos setoriais transitam em diversas áreas do conhecimento, logo,

\footnotetext{
${ }^{2}$ Ver: <www.scielo.org > e <www.periodicos.capes.gov.br >
} 
"em síntese, o problema do crescimento horizontal excessivo versus a falta de fortalecimento vertical decorre do crescimento da própria disciplina no Brasil, pois ela assumiu uma formação que mais gira em torno de áreas temáticas do que grupo de pesquisa" (Souza, 2003:16).

Souza (2003) sustenta-se em Melo (1999) novamente para apontar um terceiro problema, que diz respeito à proximidade da área de políticas públicas com a burocracia governamental, o que tanto pode resultar em trabalhos normativos e prescritivos, como a possibilidade desses mesmos órgãos governamentais ditarem a agenda de pesquisa acadêmica. Esse ponto é válido também para organismos multilaterais. Arretche (2003:8-9) afirma que o programa de pesquisa brasileiro tem estado fortemente subordinado à agenda política do país:

o conteúdo da produção acadêmica (teses, artigos e pesquisas) tem sido, em boa medida, a avaliação dos resultados alcançados pelas políticas em voga ou a atualização da informação existente sobre programas já consolidados. Na verdade, a subordinação da agenda de pesquisa à agenda política é potencialmente maior na área de políticas públicas do que em outras áreas do conhecimento (...).

Além da baixa capacidade de acumulação de conhecimento (Melo, 1999), Arretche (2003) e Souza (2003) destacam que os métodos de investigação têm recebido escassa atenção no debate dessa área de pesquisa. Nas palavras de Souza (2003:17), "a área ainda apresenta um uso excessivo de narrativas pouco pautadas por modelos ou tipologias de políticas públicas, por teorias próximas do objeto de análise e que mantêm uma leveza metodológica exagerada".

Com relação às pesquisas brasileiras, Souza (2003:17) diz que urge superar a atual geração de estudos, excessivamente concentrada nos fracassos, pouco preocupada com as questões políticas e fortemente assentada no pressuposto de que a formulação e a implementação de políticas públicas são processos exclusivamente racionais e lineares, desvinculados dos processos políticos.

Essa nova geração de estudos deve seguir na direção do desenvolvimento de tipologias analíticas, e concentrar-se na identificação das variáveis que causam impactos sobre os resultados das políticas. Isso implica na superação da dicotomia dos estudos em se analisar sucessos ou fracassos para um estágio onde se enfatize o melhor entendimento dos próprios resultados (Souza, 2003). 
No entender de Carvalho (2003:186), ao se considerar que o sistema das políticas públicas é um processo em fluxo, por associação uma dada política pública não poderia estruturar-se como seqüência linear de fases:

a abordagem que melhor expressa o quadro real das políticas públicas é a que a considera um processo contínuo de decisões que, se de um lado pode contribuir para ajustar e melhor adequar as ações ao seu objeto, de outro, pode alterar substancialmente uma política pública

Ao final de seu balanço sobre o estágio atual da disciplina de políticas públicas no Brasil, Souza (2003) comenta que já existe uma quantidade relevante de estudos sobre políticas públicas nacionais e sobre políticas locais, mas sabe-se muito pouco sobre questões cruciais na esfera estadual, como, por exemplo, as diferenças tão marcantes nas políticas formuladas e/ou implantadas pelos governos estaduais.

\section{Avaliação de políticas públicas}

Avaliar significa determinar a valia de algo, atribuir um valor (Ferreira, 1999) e outras línguas, incluindo o espanhol e o inglês, coincidem na associação de avaliação como atribuição de valor (Mokate, 2002; Garcia, 2001). No entanto, Ala-Harja e Helgason (2000) advertem, de início, que não existe consenso quanto ao que seja avaliação de políticas públicas, pois o conceito admite múltiplas definições, algumas delas contraditórias. Esse fato se explica justamente porque a área de políticas públicas é perpassada por uma variedade de disciplinas, instituições e executores, abrangendo diversas questões, necessidades e pessoas.

Ala-Harja e Helgason (2000:8) definem avaliação em termos simples, afirmando que "o termo compreende a avaliação dos resultados de um programa em relação aos objetivos propostos". ${ }^{3}$ Combinando contribuições de diversos autores, Garcia (2001:31) define avaliação:

Avaliação é uma operação na qual é julgado o valor de uma iniciativa organizacional, a partir de um quadro referencial ou padrão comparativo previa-

\footnotetext{
${ }^{3}$ Segundo Silva e Costa (2002), as políticas públicas tornam-se programas quando, por ação de uma autoridade, as condições iniciais para sua implementação se concretizam.
} 
mente definido. Pode ser considerada, também, como a operação de constatar a presença ou a quantidade de um valor desejado nos resultados de uma ação empreendida para obtê-lo, tendo como base um quadro referencial ou critérios de aceitabilidade pretendidos.

O Comitê de Assistência ao Desenvolvimento da OCDE assinala que o propósito da avaliação é determinar a pertinência e alcance dos objetivos, a eficiência, efetividade, impacto e sustentabilidade do desenvolvimento. A avaliação deve proporcionar informação que seja crível e útil para permitir a incorporação da experiência adquirida no processo de tomada de decisão. A avaliação deve ser vista como um mecanismo de melhoria no processo de tomada de decisão, a fim de garantir melhores informações, sobre as quais eles possam fundamentar suas decisões e melhor prestar contas sobre as políticas públicas (Ala-Harja e Helgason, 2000).

Thoenig (2000) declara que o uso da avaliação é orientado para ação, assim, a prioridade dela é fornecer informação. Contudo, Mokate (2002) acautela que diversas definições, inclusive a do comitê, falham em resgatar explicitamente o conceito de "valor" ou de "mérito", pois se centram na verificação do cumprimento de um plano e análise do atingimento de objetivos, supondo que o plano e os objetivos correspondentes têm um valor já reconhecido e aceito em si.

Não obstante a grande utilidade das informações provindas da avaliação, esta é muito pouco utilizada. No caso das reformas do setor público, Thoenig (2000:55) observa que nenhuma iniciativa foi lançada para avaliar as reformas; pelo contrário, "pode-se encontrar um relativo ceticismo para com a avaliação, particularmente, entre praticantes bem-informados e experientes em reforma da gestão pública, alguns até mesmo expressam uma resistência à avaliação que parece predominar no seu próprio governo".

As avaliações podem ser um "problema" para os governantes, executores e gerentes de projetos porque os resultados podem causar constrangimentos públicos. As informações e resultados das avaliações podem ser usados pelo público e pela imprensa para criticar os governos, da mesma forma que, em caso de "boas notícias", os governos podem usá-las para legitimar as próprias políticas, como ganho político etc.

\section{Breve histórico sobre a avaliação de políticas públicas}

Os esforços e estudos de avaliação de políticas públicas se desenvolveram em diversas fases. De acordo com a literatura sobre o assunto, Faria (2005) afirma 
que existe uma diversidade de maneiras de se pensar a evolução do papel atribuído à pesquisa avaliativa, desde o boom da avaliação de políticas públicas nos Estados Unidos, principalmente após a década de 1960.

Uma classificação é fornecida por Derlien (2001). Ele parte da distinção das três funções básicas atribuídas à avaliação - informação, realocação e legitimação - para dividir em três as fases evolutivas das pesquisas de avaliação, dos anos 1960 aos anos de 1990. Nos anos 1960, a ênfase política sobre a avaliação de políticas públicas preponderou sobre a função de informação. $\mathrm{O}$ foco era a melhoria dos programas, e os gerentes tinham interesse em usar a avaliação como mecanismo de feedback. A função (re)alocação foi predominante nos anos 1980, durante a segunda etapa de institucionalização, a qual estava claramente destinada a promover uma alocação racional de recursos no processo orçamentário (Derlien, 2001; Ala-Harja e Helgason, 2000).

Durante a década de 1990, a tônica política na avaliação de políticas passa a ser a função de legitimação. Esse deslocamento, segundo Derlien (2001) e Faria (2005), teria sido causado por fatores político-econômicos específicos, havendo também uma mudança dos atores dominantes. A influência da nova administração pública é percebida na década de 1990, quando os avaliadores se convertem em auditores que privilegiam a medição dos resultados. Assim, a avaliação é substituída (novos mercados internos surgem como avaliadores intrínsecos), complementada (a regulamentação de monopólios privatizados cria uma enorme demanda por avaliações) e aplicada a novas questões (novas ferramentas de avaliação, como os contratos) (Faria, 2005; Ala-Harja e Helgason, 2000).

A partir dos anos 1990, na América Latina, ocorre um questionamento crescente sobre o tamanho e a eficiência do setor público. Daí surgiram novas iniciativas para desenhar e pôr em marcha processos de avaliação (Mokate, 2002). Para Faria (2005), nas décadas de 1980 e 1990, a avaliação das políticas públicas foi posta a serviço da reforma do setor público, entretanto, a avaliação não se circunscreve a um tipo específico de Estado ou cultura administrativa.

Faria (2005:99) assinala que o desenho das reformas do setor público privilegiou dois supostos básicos:

a adoção de uma perspectiva de contenção dos gastos públicos, de busca de melhoria da eficiência e da produtividade, de ampliação da flexibilidade gerencial e da capacidade de resposta dos governos, bem como de maximização da transparência da gestão pública e de responsabilização dos gestores, em um processo no qual o "consumidor" dos bens e serviços públicos estaria, supostamente, em primeiro plano. O segundo propósito ou expectativa é de 
que tais reformas pudessem contribuir para uma reavaliação da pertinência das organizações governamentais preservarem todo o seu leque tradicional de atribuições, prevalecendo um contexto de valorização da provisão privada de bens e serviços.

Assim, a avaliação ganha centralidade porque se esperava que garantisse a credibilidade do processo de reforma e sustentabilidade política das diretrizes de desregulamentação e de diminuição do tamanho do governo, seja pelo deslocamento das funções e dos serviços para as esferas subnacionais, quer pela via da privatização (Ala-Harja e Helgason, 2000; Faria, 2005).

\section{Do "estado do campo" de avaliação de políticas públicas}

Como já descrito, a avaliação tem um papel de destaque nas reformas do setor público, assim como tem estado cada vez mais presente nos processos de análise das políticas públicas. Cabe destacar, contudo, que tal como no caso do movimento da nova administração pública, as avaliações de políticas passam atualmente por uma fase de críticas ao "gerencialismo" de suas concepções.

Wiesner Duran (citado por Mokate, 2002:90) chama a avaliação de "proxy do mercado na administração pública". Tal como apontado por Misoczky (2004), Faria (2005) reconhece a "hegemonia inconteste da perspectiva 'gerencialista"' nas discussões sobre políticas públicas (no geral) e avaliação de políticas (em específico). De acordo com esse autor, a nova ênfase dada à avaliação de políticas públicas passa quase que despercebida (pelo menos sem interesse acadêmico equivalente) pelas áreas de sociologia e ciência política, no sentido de se abrirem novos campos de pesquisa. Por outro lado, no campo da administração pública o tema é freqüente e pode ser consultado, por exemplo, em periódicos nacionais como a Revista do Serviço Público e Revista de Administração Pública. ${ }^{4}$

Apesar disso, a escassez de estudos "pós-decisão" (Faria, 2003, 2005) pode ser explicada tanto pela frágil institucionalização da área no Brasil (o que faz com que a análise de políticas públicas continue imersa nas questões analíticas tradicionalmente valorizadas pela ciência política), quanto pela "debilidade do campo de estudos da administração pública no país” (Faria, 2003:22).

\footnotetext{
${ }^{4}$ Outras instituições também têm encampado a temática, tais como o Ipea, a Fundação Seade e a Fundação Carlos Chagas.
} 
Assim, une-se à crítica esposada a notória carência de estudos dedicados aos processos e às metodologias de avaliação, que é atribuída por Faria (2003) à rara utilização da avaliação, como instrumento de gestão, pelo setor público do Brasil nas três esferas de governo. Nessa linha, se a própria avaliação tem sido relegada, o papel das idéias e do conhecimento no processo das políticas públicas tem passado praticamente em branco no país (Faria, 2003).

Se, como reverbera na literatura em políticas públicas, a avaliação tem o condão de aumentar a eficiência e eficácia do setor público, é relevante mencionar que a avaliação "ainda não logrou um papel significativo ou estratégico dentro do trabalho de desenhar e implementar estratégias, programas ou projetos" (Mokate, 2002:90). Em outras palavras, apesar do reconhecimento da avaliação como importante ferramenta, ela não se converteu em um processo indispensável que tome parte do processo de gestão (Cotta, 2001; Garcia, 2001; Mokate, 2002; Faria, 2005).

Conforme Ala-Harja e Helgason (2000), as avaliações são malvistas porque representam um universo de muitas promessas e poucas realizações. Para alguns setores, a avaliação corresponde a um novo modismo, gerador de burocracia e poucos resultados.

Cotta (2001) reconhece que o simples fato de realizar uma avaliação não significa, automaticamente, que as informações produzidas serão utilizadas. Dessa forma, para essa autora, uma resposta à posição apresentada por Ala-Harja e Helgason (2000) é que o principal motivo pelo qual a avaliação geralmente não atende às expectativas que cria é a presunção de que as condições para o aproveitamento desse tipo de informação estão dadas. "Ocorre justamente o contrário: a avaliação é uma atividade que, por suas próprias características, exige que essas condições sejam intencional e meticulosamente criadas, sob pena de comprometer todo o esforço despendido" (Cotta, 2001:94).

Faria (2005:102) aponta outros possíveis fatores que podem interferir na utilização dos resultados da avaliação: existência de crenças e interesses conflitantes na organização que gerencia o programa; ocorrência de conflitos de interesses entre as distintas unidades do programa; mudanças no pessoal encarregado (exemplo, novatos têm prioridades diferentes daquelas vigentes no início da avaliação); eventual inflexibilidade das regras e dos padrões operacionais da organização, que pode impedir a adoção das recomendações feitas quando da avaliação; mudanças nas condições externas, tais como cortes orçamentários e alterações no ambiente político.

Uma vez superados os fatores impeditivos da utilização da avaliação, Faria (2005) distingue quatro tipos de uso da avaliação: 
- instrumental - depende não apenas da qualidade da avaliação, mas também da adequada divulgação de seus resultados, sua inteligibilidade e da factibilidade das recomendações propostas;

- conceitual - as descobertas da avaliação podem alterar a maneira como esses técnicos entendem a natureza, o modo de operação e o impacto do programa que implementam. Nenhuma decisão ou ação é esperada, pelo menos não imediatamente;

- instrumento de persuasão — quando a avaliação é utilizada para mobilizar o apoio para a posição que os tomadores de decisão já têm sobre as mudanças necessárias na política ou programa;

- "esclarecimento" - "acarreta, pela via do acúmulo de conhecimento oriundo de diversas avaliações, impacto sobre as redes de profissionais, sobre os formadores de opinião e sobre as advocacy coalitions, bem como alterações nas crenças e na forma de ação das instituições" (Faria, 2005:103), orientando a agenda governamental.

Referente aos usos da avaliação, além dos diretamente envolvidos nos programas, diversos outros usuários podem se valer das descobertas da avaliação: gerentes de programas similares e/ou de diferentes níveis governamentais; agentes do governo e representantes de fundações, interessados em conhecer projetos bem-sucedidos que mereçam financiamento ou preocupados em aprimorar os programas dos quais são responsáveis; membros do Legislativo interessados na melhoria de programas existentes ou na elaboração de novas propostas; cientistas sociais e outros avaliadores que buscam aprender com as descobertas e com as metodologias empregadas (Faria, 2005).

Por fim, o interessado final é o público em geral ou a sociedade civil, a qual o governo deve ser accountable for. Dessa forma, os relatórios das avaliações podem servir tanto para divulgação, quanto para fomento do debate público em torno das alternativas de intervenção governamental em uma dada realidade social.

\section{Metodologia de avaliação de políticas públicas}

De acordo com Faria (2005), parte significativa dos estudos sobre os processos de avaliação de políticas públicas desde a década de 1960 refere-se às questões de ordem metodológica e/ou às distintas maneiras de se classificar a avaliação. Para Cotta (2001:91), a avaliação tem sido classificada "em fun- 
ção do seu timing (antes, durante ou depois da implementação da política ou programa), da posição do avaliador em relação ao objeto avaliado (interna, externa ou semi-independente) e da natureza do objeto avaliado (contexto, insumos, processo e resultados)".

Sem ordem de principalidade, uma das primeiras observações remete à diferenciação entre o timing da avaliação. A avaliação antes (ex ante) sempre foi muito estimulada e induzida nos programas financiados pelos organismos multilaterais de financiamento, especialmente aqueles voltados à infra-estrutura econômica e ao desenvolvimento urbano. Essas avaliações consistem em análises de custo-benefício, de custo-efetividade, das taxas de retorno econômico dos investimentos previstos (Lobo, 1998).

A avaliação intermediária, também chamada de formativa, é conduzida durante a implementação de um programa como meio de se adquirir mais conhecimento quanto a um processo de aprendizagem para o qual se deseja contribuir. O objetivo é dar suporte e melhorar a gestão, a implementação e o desenvolvimento do programa. A ênfase é dada à aplicabilidade direta dos resultados (Ala-Harja e Helgason, 2000).

As avaliações posteriores à implementação do programa são chamadas ex post ou somativas, e visam trabalhar com impactos e processos, portanto, estuda-se a eficácia e o julgamento do valor geral do programa. A objetividade e a credibilidade dos achados são mais importantes que a aplicabilidade direta dos resultados (Lobo, 1998; Ala-Harja e Helgason, 2000).

No que diz respeito à posição do avaliador ante o objeto avaliado, Arretche (1998) defende que, porque destinadas a exercer controle sobre as intervenções públicas, seja dos cidadãos sobre o governo, seja do governo sobre si mesmo, as avaliações precisam ser conduzidas por órgãos independentes. O ponto em questão é a neutralidade da avaliação. Para a autora, é muito difícil que avaliações realizadas pelas próprias equipes governamentais encarregadas da execução de uma dada política sejam críveis e isentas (embora a neutralidade absoluta seja impossível).

Há uma série de incentivos para que tais avaliações concluam pelo sucesso do programa ou, pelo menos, que tendam a minimizar seus elementos de fracasso. Tais razões vão desde a manutenção dos próprios empregos até o interesse das burocracias em aumentar suas margens de poder e de gasto. Por isso, é mais difícil que tais "avaliações" tenham em geral valor avaliativo, ainda que possam ser bons instrumentos de pesquisa para estudos de avaliação, mais particularmente avaliações de eficácia (Arretche, 1998:37-38).

É impossível prevenir erros em julgamentos ou tendências na forma como o homem pensa ou age. Em vista disto, Henry (2002) defende que o ide- 
al é tornar as decisões transparentes e identificar os participantes nas decisões e suas afiliações ideológicas. Com essas informações em mãos as tendências podem ser confrontadas. O mesmo deve valer para os resultados de avaliações que, além da transparência, devem ser amplamente disponíveis, com descrição do desenho do estudo e os processos.

Henry (2002) oferece pelo menos duas razões para transparência dos processos de avaliação de políticas públicas. O primeiro motivo é o aprendizado decorrente do trabalho de outros pesquisadores, substantiva e metodologicamente. De acordo com o autor (2002:424), "evaluation reports should make the methods for systematic inquiry transparent, as the best reports do currently". A segunda razão apontada é demonstrar mais sistematicamente os benefícios de processos específicos que podem ser usados para selecionar indicadores de sucesso, como diálogos deliberativos, negociações com os usuários ou stakeholders.

Nas palavras de Henry (2002:421), "to stand up in the contentious environs of modern democracies, evaluation must be perceived as producing credible information that is not unduly biased by its sponsor or by bad decisions of the evaluator (...)". Continuando com Henry (2002:425)

Without making evaluations transparent, we are forced into arguments that can gain no traction because of information asymmetry; that is, those who have used the approaches have complete control over what information is available to those who are considering the use or adaptation of the approaches.

Assim, as avaliações podem ser discutidas em uma arena pública, onde os cidadãos têm pleno acesso às informações, à metodologia empregada e aos resultados alcançados. A avaliação torna-se, assim, um verdadeiro instrumento democrático de controle sobre a ação dos governos (Arretche, 1998).

Arretche (1998) assevera que a literatura de avaliação de políticas públicas costuma distingui-la em termos de sua eficácia, eficiência e efetividade, recurso analítico destinado a separar aspectos distintos dos objetivos, da abordagem e dos métodos e técnicas de avaliação.

Uma postura mais abrangente sobre a metodologia de avaliação de políticas públicas é exposta por Costa e Castanhar (2003). Os autores partem do pressuposto que se avaliação é uma forma de mensuração, de julgamento de valor, é preciso estabelecer, antes de tudo, os critérios de avaliação, e nesse ponto não há consenso sobre aspectos metodológicos e conceituais. O que existe é um autêntico "emaranhado conceitual". 
A lista de critérios é longa e a escolha de um, ou vários deles, depende do que se deseja privilegiar na avaliação. Com fulcro no manual da Unicef, ${ }^{5}$ Costa e Castanhar (2003:973) listam os mais comuns: eficiência, eficácia, impacto (efetividade), sustentabilidade, análise custo-efetividade, satisfação do usuário, eqüidade.

No entanto, a aplicação dos critérios depende de operacionalização para identificação e quantificação dos resultados obtidos. A operacionalização pode ser feita, segundo Costa e Castanhar (2003), por meio de indicadores. O termo indicador é derivado da palavra latina indicare, que significa "tornar patente; demonstrar, revelar, denotar; expor" (Ferreira, 1999). Para a OCDE, um indicador deve ser compreendido como um parâmetro, ou valor derivado de parâmetros que forneçam informações sobre o estado de um fenômeno, com uma extensão significativa (van Bellen, 2005).

Tendo em mente os critérios e indicadores a serem utilizados, resta fazer as comparações com o referencial, tal como aludido por Garcia (2001). Os padrões de referência para guiar a avaliação podem ser classificados em: absolutos (as metas estabelecidas são consideradas como o padrão a ser alcançado), históricos (comparação dos resultados ao longo do tempo), normativos (comparação do desempenho com programas similares ou semelhantes), teóricos (estabelecidos na própria elaboração do programa, sob a hipótese da obtenção dos resultados planejados), negociados ou de compromisso (baseiam-se em algum procedimento específico para sua fixação, normalmente decorrente de consensos entre as partes envolvidas na gestão e os formuladores) (Costa e Castanhar, 2003).

O desenho de um programa público pode ser sintetizado em uma seqüência de definições correspondentes a graus sucessivos de agregação de objetivos. A tradição brasileira costuma organizar, segundo Costa e Castanhar (2003), de maneira hierarquizada, a seqüência de compromissos de um programa público da seguinte forma: propósito $>$ objetivo $>$ meta $>$ atividade.

Atualmente maior atenção tem sido dada a uma metodologia de estruturação de políticas públicas chamada metodologia do marco lógico. ${ }^{6}$ Esta metodologia parte da concepção de políticas públicas como processos articulados e estabelece os recursos que configuram a política pública, seus

\footnotetext{
${ }^{5}$ The United Nations Children's Fund (em português, Fundo das Nações Unidas para a Infância).

${ }^{6}$ Também chamada de matriz lógica (Costa e Castanhar, 2003) e marco conceitual (Mokate, 2002).
} 
programas e projetos, e encadeiam as etapas de um mesmo programa, desde o diagnóstico da população-alvo até a definição de critérios para intervenção (Carvalho, 2003).

A ferramenta de base se estrutura em forma de uma matriz de organização: de um lado ficam os objetivos, indicadores, meios de aferição e fatores externos a influenciar os resultados do programa; de outro, a especificação dos objetivos geral e específicos, componentes e atividades (Carvalho, 2003).

Outra forma de se estruturar a matriz lógica é dada por Costa e Castanhar (2003): começa-se pela identificação dos objetivos gerais e específicos do programa e dos indicadores pelos quais o programa será avaliado, assim como a identificação das fontes de dados que serão usadas para as mensurações, comparações e análises. Num segundo momento volta-se para a identificação dos recursos (financeiros, humanos, infra-estrutura) alocados ao programa, as atividades previstas, os resultados esperados e as relações causais que a teoria por trás do programa pressupõe que podem ser atingidas.

Um exemplo de modelo lógico, para primeira etapa descrita por esses autores, relacionando objetivo do projeto, variáveis operacionais, indicadores, informação necessária e forma de obtenção dos dados é apresentado na tabela 1 .

Tabela 1

Exemplo parcial da primeira etapa do modelo lógico

\begin{tabular}{|lllll|}
\hline Objetivo & Variável & Indicador & $\begin{array}{l}\text { Informação } \\
\text { necessária }\end{array}$ & $\begin{array}{c}\text { Método de } \\
\text { coleta } \\
\text { de dados }\end{array}$ \\
\hline $\begin{array}{l}\text { Aumentar a } \\
\text { produção agrícola } \\
\text { dos beneficiários do } \\
\text { projeto }\end{array}$ & $\begin{array}{l}\text { Volume da } \\
\text { produção agrícola }\end{array}$ & $\begin{array}{l}\text { Quantidade } \\
\text { produzida por } \\
\text { cultura }\end{array}$ & $\begin{array}{l}\text { Dados sobre } \\
\text { produção }\end{array}$ & $\begin{array}{l}\text { Pesquisa } \\
\text { secundária } \\
\text { (anuários de } \\
\text { produção) }\end{array}$ \\
& $\begin{array}{l}\text { Valor da } \\
\text { produção agrícola }\end{array}$ & & $\begin{array}{l}\text { Dados sobre } \\
\text { receita } \\
\text { financeira }\end{array}$ & $\begin{array}{l}\text { Pesquisa de } \\
\text { campo }\end{array}$ \\
\hline
\end{tabular}

Fonte: Costa e Castanhar, 2003: 978.

A identificação de recursos do programa, as atividades e os resultados esperados (imediatos, médio e longo prazos) pode ser visualizada no exemplo da tabela 2. 
Tabela 2

\section{Exemplo da segunda etapa do modelo lógico em projetos de agricultura irrigada fatores contextuais}

\begin{tabular}{|c|c|c|c|c|}
\hline $\begin{array}{l}\text { Inputs do } \\
\text { programa }\end{array}$ & $\begin{array}{c}\text { Atividades do } \\
\text { programa }\end{array}$ & $\begin{array}{l}\text { Resultados } \\
\text { imediatos }\end{array}$ & $\begin{array}{l}\text { Resultados } \\
\text { (impactos) de } \\
\text { médio prazo }\end{array}$ & $\begin{array}{c}\text { Resultados } \\
\text { (impactos) de } \\
\text { longo prazo }\end{array}$ \\
\hline \multirow[t]{2}{*}{$\begin{array}{l}\text { Recursos } \\
\text { financeiros }\end{array}$} & $\begin{array}{l}\text { Financiamento à } \\
\text { produção }\end{array}$ & $\begin{array}{l}\text { Mudança } \\
\text { nos sistemas } \\
\text { produtivos }\end{array}$ & $\begin{array}{l}\text { Instalação de } \\
\text { agroindústrias e } \\
\text { serviços correlatos }\end{array}$ & $\begin{array}{l}\text { Mudança nos } \\
\text { padrões de vida } \\
\text { das populações } \\
\text { beneficiadas }\end{array}$ \\
\hline & $\begin{array}{l}\text { Apoio à } \\
\text { comercialização }\end{array}$ & $\begin{array}{l}\text { Melhoria de } \\
\text { volume de } \\
\text { produção }\end{array}$ & $\begin{array}{l}\text { Mudanças nos } \\
\text { sistemas de } \\
\text { comercialização da } \\
\text { produção }\end{array}$ & $\begin{array}{l}\text { Redução da } \\
\text { ingerência do } \\
\text { setor público } \\
\text { na operação do } \\
\text { programa }\end{array}$ \\
\hline $\begin{array}{l}\text { Pessoal } \\
\text { alocado ao } \\
\text { programa }\end{array}$ & $\begin{array}{l}\text { Treinamento } \\
\text { Assistência } \\
\text { técnica }\end{array}$ & $\begin{array}{l}\text { Melhoria de } \\
\text { renda }\end{array}$ & $\begin{array}{l}\text { Aumento nos níveis } \\
\text { de associação e } \\
\text { integração entre os } \\
\text { usuários }\end{array}$ & \\
\hline & $\begin{array}{l}\text { Apoio à } \\
\text { comercialização }\end{array}$ & & & \\
\hline $\begin{array}{l}\text { Recursos de } \\
\text { treinamento } \\
\text { (material } \\
\text { instrucional) }\end{array}$ & $\begin{array}{l}\text { Treinamento } \\
\text { Assistência } \\
\text { técnica }\end{array}$ & $\begin{array}{l}\text { Manutenção } \\
\text { de níveis } \\
\text { adequados de } \\
\text { endividamento }\end{array}$ & & \\
\hline Infra-estrutura & $\begin{array}{l}\text { Realização } \\
\text { de obras de } \\
\text { irrigação }\end{array}$ & & & \\
\hline Equipamentos & $\begin{array}{l}\text { Aquisição e } \\
\text { distribuição de } \\
\text { equipamentos } \\
\text { para irrigação }\end{array}$ & $\begin{array}{l}\text { Manutenção de } \\
\text { níveis adequados } \\
\text { de arrecadação } \\
\text { x custos de } \\
\text { operação }\end{array}$ & & \\
\hline $\begin{array}{l}\text { Produtores } \\
\text { rurais elegíveis } \\
\text { para o projeto }\end{array}$ & $\begin{array}{l}\text { Cadastramento } \\
\text { e identificação } \\
\text { dos perfis dos } \\
\text { beneficiários }\end{array}$ & $\begin{array}{l}\text { Manutenção de } \\
\text { níveis mínimos } \\
\text { de inadimplência } \\
\text { Manutenção de } \\
\text { níveis mínimos } \\
\text { de transferência } \\
\text { de lotes }\end{array}$ & & \\
\hline
\end{tabular}

Fonte: Costa e Castanhar, 2003: 977-978. 
Os fatores contextuais dizem respeito aos aspectos que estão fora do controle da equipe de planejamento e gestão do programa, porém podem exercer impacto positivo ou negativo sobre os resultados, tais como: características empreendedoras dos beneficiários, perfis de gerentes envolvidos na execução do projeto, características e atuação dos líderes comunitários.

Conforme Carvalho (2003:193), a metodologia do marco lógico se destaca pela clareza na distinção dos conceitos de avaliação e das atividades necessárias para seu desenvolvimento, bem como na proposição de dimensões para avaliação, "possibilitando resultados analíticos baseados em uma interpretação integrada do comportamento dos agentes, das atribuições das instâncias de implementação e da interação com as populações potencial e beneficiária".

Diante dos diversos objetivos de uma avaliação de política pública, podem-se distinguir três modalidades de avaliação: avaliação de metas, avaliação de processos e avaliação de impacto (Garcia, 2001; Carvalho, 2003; Costa e Castanhar, 2003).

A avaliação de metas tem como propósito mensurar o grau de êxito que um programa alcança. As metas de um programa são os resultados mais imediatos que dele decorrem (número de pessoas atendidas em centros de saúde, número de horas de aula, número de leitos hospitalares). Trata-se, pois, de uma avaliação ex post facto, visto que pressupõe a atribuição de valores a um conjunto de metas, definindo-se o êxito do programa em função de que tais metas tenham sido cumpridas. Algumas limitações desse tipo de avaliação são: dificuldade de especificar as metas de forma precisa; seleção de metas a serem incluídas no processo de avaliação; mudanças nas metas ao longo da própria execução do programa (Costa e Castanhar, 2003).

A avaliação de processo visa detectar defeitos na elaboração dos procedimentos, acompanhar e avaliar a execução dos procedimentos de implantação dos programas, identificar barreiras e obstáculos à sua implementação e gerar dados para sua reprogramação, por meio do registro de intercorrências e de atividades. Essa avaliação se realiza concomitantemente ao desenvolvimento do programa, portanto, o uso adequado das informações produzidas permite incorporar mudanças ao seu conteúdo (Carvalho, 2003; Costa e Castanhar, 2003).

Já a avaliação de impacto, conforme Carvalho (2003:186), "é aquela que focaliza os efeitos ou impactos produzidos sobre a sociedade e, portanto, para além dos beneficiários diretos da intervenção pública, avaliando-se sua efetividade social". Busca-se nessa avaliação detectar as mudanças que efetivamente ocorreram e em que medida as mudanças ocorreram na direção desejada. De acordo com a autora, dois pressupostos orientam a avaliação de 
impacto: o primeiro reconhece propósitos de mudança social na política em análise e, dessa forma, faz sentido configurar a investigação para mensurar seus impactos; o segundo pressuposto é o que estrutura a análise com base em uma relação causal entre o programa e a mudança social provocada.

Não basta constatar a ocorrência de mudança, é preciso estabelecer a relação causa-efeito entre as ações de um programa e o resultado final obtido; entre essas e a ação pública realizada por meio da política (Garcia, 2001; Carvalho, 2003; Costa e Castanhar, 2003). Por sua natureza avaliativa ela é considerada ex post facto.

Por fim, a avaliação, como instrumental de análise, pode-se valer também dos métodos próprios da pesquisa social. A sua escolha, entretanto, não é casual nem mesmo predeterminada, pois o pressuposto é que seja conforme os objetivos (explícitos ou implícitos) estabelecidos pela política (Carvalho, 2003).

Um último comentário merece ser prestado aos estudos de avaliação de avaliações, ou metaavaliações. Segundo Henry (2001), em algum momento os avaliadores também serão responsabilizados (accountable) pelas suas decisões. Mais provavelmente, os avaliadores serão responsabilizados não apenas em adotar procedimentos-padrão, mas pelos seus resultados e pelos impactos de seus achados. Para esse autor, o futuro da metaavaliação passará a focar com mais intensidade as avaliações individuais - durante o processo, os critérios para definir o que é certo nas avaliações individuais serão melhorados, criticados, revisados e, talvez, aceitos.

Conforme Henry (2001), o interesse em metaavaliações pode produzir duas linhas importantes de trabalhos para o campo. Em primeiro lugar, um resultado muito positivo poderia ser um conjunto de estudos empíricos que examinam os impactos verdadeiros das avaliações. A segunda contribuição das meta avaliações diz respeito às revisões de avaliações individuais. Henry (2001) assinala que os métodos para testar avaliações específicas devem trazer à luz preconceitos e inclinações quando eles ocorrerem e devem fazer com que esses achados sejam acessíveis. Além disso, "eventually, to engender confidence in the independence of these reviews, the methods must not only be capable of a determination of bias, they must actually determine some instances in which it has actually occurred" (Henry, 2001:426).

\section{Considerações finais}

As últimas décadas têm registrado o ressurgimento e crescimento do campo de conhecimento das políticas públicas, em especial no Brasil. Esse novo fô- 
lego deve-se em grande parte às alterações históricas, políticas e econômicas vivenciadas pela sociedade, e encaradas pelos governos como desafios, que se traduziram em modificações sobre a forma de compreender, formular e avaliar as próprias políticas.

Nesse veio, conforme levantado pela literatura em avaliação de políticas públicas, a função de avaliação sofreu deslocamentos teórico-discursivos, tomando-se como ponto de partida a década de 1960. Nesse período, a ênfase política sobre a avaliação concentrou-se no fornecimento de informação para os gerentes de programas públicos, de forma a garantir feedbacks para correções de rumo. Na década de 1980, a avaliação pende para a função de (re)alocação, ou seja, buscava-se eficiência na alocação de recursos com base em critérios racionais do processo orçamentário.

A década de 1990 marca a última fase evidenciada pela literatura, na qual o deslocamento teórico-discursivo é fortemente marcado pelo questionamento do papel do Estado, aliado à influência da nova administração pública. A avaliação assume a função de legitimação, ao mesmo tempo em que são exigidos resultados da administração e das políticas públicas.

Inovações e refinamentos teóricos com relação a metodologias de avaliação acompanharam e acompanham de perto as concepções e funções das políticas públicas. Nesse sentido, os esforços de pesquisa na avaliação de políticas apontam para uma maior estruturação e sistematização dos programas, tal como visto com a metodologia do marco lógico.

Contudo, outros questionamentos sobre a avaliação de políticas públicas se colocam, lentamente, na agenda de pesquisas acadêmicas. Assim como o movimento da nova administração pública vem sofrendo pressões sobre seu caráter democrático-participativo (ou falta dele), está em aberto o debate sobre novas formas de accountability e participação social sobre a avaliação de políticas públicas no contexto democrático brasileiro.

\section{Referências bibliográficas}

ALA-HARJA, Marjukka; HELGASON, Sigurdur. Em direção às melhores práticas de avaliação. Revista do Serviço Público, Brasília, v. 51, n. 4, p. 5-59, out./dez. 2000.

ARRETCHE, Marta. Dossiê agenda de pesquisa em políticas públicas. Revista Brasileira de Ciências Sociais, São Paulo, v. 18, n. 51, p. 7-9, fev. 2003.

. Tendências no estudo sobre avaliação. In: RICO, Elizabeth Melo (Org.). Avaliação de políticas sociais: uma questão em debate. São Paulo: Cortez, 1998. p. 29-39. 
CARVALHO, Sonia Nahas de. Avaliação de programas sociais: balanço das experiências e contribuição para o debate. São Paulo em Perspectiva, São Paulo, v. 17, n. 3-4, p. 185-197, jul./dez. 2003.

COSTA, Frederico Lustosa da; CASTANHAR, José Cezar. Avaliação de programas públicos: desafios conceituais e metodológicos. Revista de Administração Pública, Rio de Janeiro, v. 37, n. 5, p. 962-969, set./out. 2003.

COTTA, Tereza Cristina. Avaliação educacional e políticas públicas: a experiência do Sistema Nacional de Avaliação da Educação Básica (Saeb). Revista do Serviço Público, Brasília, v. 52, n. 4, p. 89-110, out./dez. 2001.

DERLIEN, Hans-Ulrich. Una comparación internacional en la evaluación de las políticas públicas. Revista do Serviço Público, Rio de Janeiro, v. 52, n. 1, p. 105-122, jan./mar. 2001.

FARIA, Carlos Aurélio Pimenta de. A política da avaliação de políticas públicas. Revista Brasileira de Ciências Sociais, São Paulo, v. 20, n. 59, p. 97-109, out. 2005.

. Idéias, conhecimento e políticas públicas: um inventário sucinto das principais vertentes analíticas recentes. Revista Brasileira de Ciências Sociais, São Paulo, v. 18, n. 51, p. 21-29, fev. 2003.

FERREIRA, Aurélio Buarque de Holanda. Dicionário Aurélio Eletrônico: século XXI. Rio de Janeiro: Nova Fronteira, 1999. versão 3.0. CD-ROM.

FREY, Klaus. Políticas públicas: um debate conceitual e reflexões referentes à prática da análise de políticas públicas no Brasil. Planejamento e Políticas Públicas, Brasília, n. 21, p. 211-259, jun. 2000.

GARCIA, Ronaldo Coutinho. Subsídios para organizar avaliações da ação governamental. Planejamento e Políticas Públicas, Brasília, n. 23, p. 7-70, jan./jun. 2001.

HENRY, Gary T. How modern democracies are shaping evaluation and the emerging challenges for evaluation. American Journal of Evaluation, v. 22, n. 3, p. 419-429, Sept. 2001.

JOBERT, Bruno; MULLER, Pierre. L'Etat en action. Paris: PUF, 1987.

LOBO, Thereza. Avaliação de processos e impactos em programas sociais: algumas questões para reflexão. In: RICO, Elizabeth Melo (Org.). Avaliação de políticas sociais: uma questão em debate. São Paulo: Cortez, 1998. p. 75-84.

MELO, Marcus André. As sete vidas da agenda pública brasileira. In: RICO, Elizabeth Melo (Org.). Avaliação de políticas sociais: uma questão em debate. São Paulo: Cortez, 1998. p. 11-28. 
. Estado, governo e políticas públicas. In: MICELI, Sérgio (Org.). O que ler na ciência social brasileira (1970-1995). São Paulo: Sumaré, 1999. v. 3, p. 59-100.

MISOCZKY, Maria Ceci. Uma defesa da reflexão teórico-crítica na pesquisa e prática da administração pública. In: ENCONTRO DE ADMINISTRAÇÃO PÚBLICA E GOVERNANÇA, 1., 2004, Rio de Janeiro. Anais... Rio de Janeiro: Anpad, 2004. p. 1-14. CD-ROM.

MOKATE, Karen Marie. Convirtiendo el "monstruo" en aliado: la evaluación como herramienta de la gerencia social. Revista do Serviço Público, Brasília, v. 53, n. 1, p. 89-131, jan./mar. 2002.

REIS, Elisa P. Reflexões leigas para a formulação de uma agenda de pesquisa em políticas públicas. Revista Brasileira de Ciências Sociais, São Paulo, v. 18, n. 51, p. 11-14, fev. 2003.

SILVA, Pedro Luiz Barros; COSTA, Nilson do Rosário. A avaliação de programas públicos: reflexões sobre a experiência brasileira. Brasília: Ipea, 2002.

SOUZA, Celina. "Estado do campo" da pesquisa em políticas públicas no Brasil. Revista Brasileira de Ciências Sociais, São Paulo, v. 18, n. 51, p. 15-20, fev. 2003.

THOENIG, Jean-Claude. A avaliação como conhecimento utilizável para reformas de gestão pública. Revista do Serviço Público, Brasília, v. 51, n. 2, p. 54-70, abr./jun. 2000.

VAN BELLEN, Hans Michael. Indicadores de sustentabilidade: uma análise comparativa. Rio de Janeiro: FGV, 2005. 